\title{
Analysis of Color and Hardness of a Medical Silicone with Extrinsic Pigmentation after Accelerated Aging
}

\author{
Daniela Micheline dos Santos ${ }^{1} \quad$ Marcela Borgui Paulini ${ }^{1} \quad$ Tamires Gabrielle Silva Faria ${ }^{1}$ \\ Clovis Lamartine de Moraes Melo Neto ${ }^{1, \odot ~ E m i l y ~ V i v i a n n e ~ F r e i t a s ~ d a ~ S i l v a ~}{ }^{1} \quad$ Fernanda Pereira de Caxias ${ }^{1}$ \\ André Pinheiro de Magalhães Bertoz ${ }^{2}$ Marcelo Coelho Goiato ${ }^{1}$ \\ ${ }^{1}$ Department of Dental Materials and Prosthodontics, São Paulo \\ State University, School of Dentistry, Araçatuba, São Paulo, Brazil \\ ${ }^{2}$ Department of Pediatric and Social Dentistry, São Paulo State \\ University, School of Dentistry, Araçatuba, São Paulo, Brazil

\begin{abstract}
Address for correspondence Marcelo Coelho Goiato, DDS, MS, $\mathrm{PhD}$, São Paulo State University, Department of Dental Materials and Prosthodontics, José Bonifácio, 1193 Vila Mendonça, Araçatuba, São Paulo 16015-050, Brazil

(e-mail: m.goiato@unesp.br).
\end{abstract}

Eur J Dent:2020;14:634-638

\begin{abstract}
Keywords

- prosthesis

- maxillofacial prosthesis

- silicone elastomers

Objective The aim of this study is to evaluate the color alteration and shore A hardness of a medical silicone with extrinsic pigmentation, before and after accelerated aging.

Materials and Methods Twenty samples (Silastic Q7-4735) were made with an intrinsic pigmentation. This intrinsic pigmentation was composed of a pink pigment (H-109-P, Factor II) and an opacifier (ZnO). All samples had standardized dimensions (45-mm diameter and 2-mm thickness). Half of the 20 samples manufactured subsequently received an extrinsic pigment (Tan FE-215, Factor II). Therefore, two groups were created $(n=10)$ : Group 1, group with intrinsic pigmentation and without extrinsic pigmentation (control) and Group 2, group with intrinsic and extrinsic pigmentation. Samples were submitted to color and Shore A hardness tests, before and after 1,008 hours of aging.

Statistical Analysis Color alteration data were submitted to Student's $t$-test $(\alpha=0.05)$. Shore A hardness data were submitted to two-way analysis of variance and Tukey test $(\alpha=0.05)$.

Results The incorporation of the extrinsic pigment on the silicone did not affect its color $(\Delta \mathrm{E})$ when the two groups were compared $(p=0.232)$. Regarding the hardness test, the interaction between group and period did not interfere with the hardness results $(p=0.599)$. However, the period factor showed that there was a reduction in the hardness of the silicone after aging $(p<0.05)$.

Conclusion In this study, all the hardness and color results of the silicone used were clinically acceptable, regardless of the presence of extrinsic pigmentation.
\end{abstract}

\section{Introduction}

Facial defects are usually caused by cancer, traumatic accidents, or congenital diseases and can affect speech, quality of life, and the psychological state of an individual. ${ }^{1}$ Maxillofacial prostheses can be used to mask these facial defects, ${ }^{1}$ improve aesthetics, ${ }^{2-9}$ quality of life, and self-esteem of the patients, 3,5 in addition to protecting areas that contain bloody tissues. ${ }^{3,5}$ These prostheses also allow many patients with orofacial defects to return to their daily activities in public. $^{3,10}$

The silicone elastomer for external prostheses was first used in $1960 .{ }^{11,12}$ Subsequently, silicone has become the most used material in the manufacture of maxillofacial prostheses. ${ }^{3,8-13}$ According to Nobrega et al, silicone elastomers are biocompatible, easy to manipulate, chemically inert, 
relatively strong, flexible, translucent, esthetic, comfortable, and stable when exposed to heat. ${ }^{5}$ In addition, they repel water, blood, and organic materials. ${ }^{3,5}$ Unfortunately, the clinical deterioration of a silicone prosthesis usually occurs from $3^{3,5,10}$ to 12 months $s^{2,4-7,10,13}$ after its manufacture. This deterioration occurs due to intrinsic ${ }^{7,14}$ and extrinsic factors. ${ }^{1-3,7,8,10,13-17}$

The most common reason why a patient does not like his or her silicone prosthesis is due to its color fading. ${ }^{10}$ Thus, color degradation is a reason to remake a silicone facial prosthesis. ${ }^{6}$ In addition to color, another important property is the hardness. According to some authors, the hardness of a silicone determines its flexibility and allows the prosthesis to mimic the human skin texture, providing greater comfort for the patient. ${ }^{3,13}$ Therefore, these two properties are extremely important for a maxillofacial silicone prosthesis.

The silicones can be stained intrinsically and/or extrinsically to give them more lifelike natural appearance. ${ }^{18}$ Due to the lack of studies in the literature evaluating color stability and hardness of silicones that received extrinsic pigmentation, the present study aimed to evaluate the color stability and Shore A hardness of a medical silicone with extrinsic pigmentation, before and after accelerated aging.

\section{Materials and Methods}

\section{Preparation of Samples}

Twenty silicone samples (Silastic Q7-4735; Dow Corning Corporation, Michigan, United States) were made with an intrinsic pigmentation. This intrinsic pigmentation was composed of a pink pigment (H-109-P; Factor II, United States) and an opacifier ( $\mathrm{ZnO}$ nanoparticles). A metallic matrix was used to manufacture the samples. All samples had standardized dimensions (45-mm diameter and 2-mm thickness)., Half of the 20 samples manufactured subsequently received an extrinsic pigment (Tan FE-215; Factor II, United States). Therefore, two groups were created: Group 1, group with intrinsic pigmentation (H-109-P, Factor II and $\mathrm{ZnO}$ opacifier) and without extrinsic pigmentation (control); and Group 2, group with intrinsic (H-109-P, Factor II and $\mathrm{ZnO}$ opacifier) and extrinsic pigmentation (Tan FE-215, Factor II).

The pigment and opacifier were weighed by using an analytical balance (BEL Analytical Equipment, Brazil). The intrinsic pigment corresponded to $0.2 \%$ of the silicone weight. 5,7, $, 13,14,16,17$ The intrinsic opacifier $(\mathrm{ZnO})$ corresponded to $2 \%$ of the silicone weight. ${ }^{3}$ The silicone was manipulated at $23 \pm 2^{\circ} \mathrm{C}$ with a relative humidity ${ }^{5,7-9,13,14,16,17}$ of $50 \pm 10 \% .14,16,17$ The base and catalyst paste were mixed according to the manufacturer's recommendations until the paste becomes homogeneous. Then, a pink pigment (H-109-P, Factor II) and an opacifier $(\mathrm{ZnO})$ were added to the colorless silicone paste. Subsequently, the silicone was poured into a metallic matrix. The matrix was closed and submitted to $1,000 \mathrm{kgf}$ in a hydraulic press (Maxx II; Essence Dental VH, Brazil) for 10 minutes. Then, the metallic matrix was inserted into a sterilization and drying oven (SolidSteel, Brazil) at a temperature of $116^{\circ} \mathrm{C}$ for 10 minutes to complete the polymerization of the material.
Subsequently, an extrinsic pigment was applied to half of the samples. The extrinsic pigment (Tan FE-215, Factor II) was diluted in 1,1,1-trichloroethane (I-301 Extrinsic Tri-Fluid; Factor II, United States) in the proportion of $1 \mathrm{~mL}$ (extrinsic pigment) to $1 \mathrm{~mL}$ (1,1,1-trichloroethane). This extrinsic pigment (Tan FE-215, Factor II) diluted in 1,1,1-trichloroethane (I-301 Extrinsic Tri-Fluid, Factor II) was uniformly sandblasted on the surface of the Group 2 samples with the help of an airbrush (WIMPEL, Brazil). Subsequently, the extrinsic paint was sealed following the manufacturer's recommendations. The extrinsic pigment (Tan FE-215, Factor II) corresponded to $0.2 \%$ of the silicone weight.

\section{Color Stability and Shore A Hardness Tests}

Both groups were submitted to color stability and Shore A hardness tests, before and after accelerated aging. The color readings were taken using a spectrophotometer of visible ultraviolet reflection (UV-2450, Shimadzu, Japan).5,14,15,17 Color alteration $(\Delta \mathrm{E})$ was calculated by the Commission Internationale de L'Eclairage (CIE) L*a* $\mathrm{b}^{*}$ system, established by the CIE. This system can be calculated according to the formula: $\Delta \mathrm{E}=\left[(\Delta \mathrm{L})^{2}+(\Delta \mathrm{a})^{2}+(\Delta \mathrm{b})^{2}\right]^{1 / 2}$. 5-7, 14,15,17,19-23 The "L" represents brightness from 0 (black) to 100 (perfect white), the "a" represents the amount of red (positive values) or green (negative values), and the "b" represents the amount of yellow (positive values) or blue (negative values), ${ }^{5,7,17,21,23}$ Color readings were taken before and after accelerated aging.

The hardness test evaluation (Shore A) was performed using a digital durometer (GSD 709 Teclock, Japan), according to American Society for Testing and Materials, Designation D2240. ${ }^{2,3,8,13}$ The needle penetrated the samples at a load of $10 \mathrm{~N} .{ }^{3,8,13}$ The measurement was established between 0 and 100 Shore $A$, with $\pm 1 \%$ of tolerance. ${ }^{8}$ The hardness values were expressed in Shore A units., ${ }^{2,3,8,13}$ Each sample was positioned on the stand of the hardness meter at a distance of $\pm 2 \mathrm{~mm}$ from the penetration tip of the appliance. ${ }^{8}$ The penetration tip applied pressure for 15 seconds on the samples. ${ }^{8}$ Three measurements were performed on each sample, before and after accelerated aging. Subsequently, a mean was obtained from the three measurements made on each sample.

All samples were submitted to the accelerated aging test using an accelerated aging chamber (Equilam, Brazil). Accelerated aging was performed according to the American Society for Testing and Materials, Designation G53-96. ${ }^{24}$ The samples were subjected to alternating periods of ultraviolet B light (UVB-313 lamps, 40 Watts, Equilam) and condensation of distilled water under the conditions of heat and 100\% humidity. ${ }^{3,5,7,9,13-17}$ Each aging cycle was performed for 12 hours. In the first 8 hours, the temperature was maintained at $60 \pm 3^{\circ} \mathrm{C}$, and the ultraviolet B light was imputed

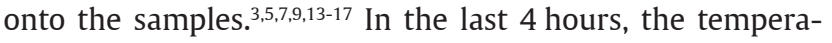
ture was maintained at $45 \pm 3^{\circ} \mathrm{C}$ and a condensation period occurred without ultraviolet B light., 3,7,7,13-17 This process simulated the deterioration caused by rainwater, dew, and ultraviolet light from the sun. $3,5,7,9,14-17$ The aging was performed for a total of 1,008 hours. $3,5,7,9,16$ 


\section{Statistical Analysis}

All data were analyzed using the Statistical Package for Social Sciences 20.0 (SPSS-IBM Corp., United States). Color alteration data were submitted to the Student's t-test $(\alpha=0.05)$. Shore A hardness data were submitted to the two-way repeated measures analysis of variance and the Tukey test $(\alpha=0.05)$.

\section{Results}

The incorporation of the extrinsic pigment on the silicone did not affect its color $(\Delta \mathrm{E})$ when the two groups were compared $(p=0.232 ;$ - Table 1$)$.

Regarding the hardness test, the interaction between group and period did not interfere with the hardness results $(p=0.599)$. However, the period factor showed that there was a reduction in the hardness of the silicone after aging $(p<0.05)$ ( - Table 2 and $\mathbf{3})$.

\section{Discussion}

The degradation of a silicone can cause changes in its physical and mechanical properties, ${ }^{2,5}$ such as color alteration and surface hardness. The color alteration and hardness of a silicone may be caused by intrinsic and extrinsic factors. The intrinsic factor is related to changes in the silicone matrix,

Table 1 Color alteration $(\Delta \mathrm{E})$ and standard deviation for groups with and without extrinsic pigmentation

\begin{tabular}{|l|l|l|l|}
\hline Groups & Mean & $\begin{array}{l}\text { Standard } \\
\text { deviation }\end{array}$ & $p$-Value \\
\hline $\begin{array}{l}\text { Group 1 (without extrinsic } \\
\text { pigmentation) }\end{array}$ & 2.42 & 0.40 & 0.232 \\
\hline $\begin{array}{l}\text { Group 2 (with extrinsic } \\
\text { pigmentation) }\end{array}$ & 2.12 & 0.66 & \\
\hline
\end{tabular}

Note: Student's t-test, $p<0.05$.

Table 2 Means of Shore A hardness and standard deviation of silicone regardless of pigmentation method

\begin{tabular}{|l|l|l|}
\hline Period & Mean & $\begin{array}{l}\text { Standard } \\
\text { deviation }\end{array}$ \\
\hline Initial & $36.20 \mathrm{a}$ & 3.10 \\
\hline Final & $34.15 \mathrm{~b}$ & 1.59 \\
\hline
\end{tabular}

Note: Different letters indicate significant statistical difference (Tukey's test, $p<0.05)$. causing its degradation. ${ }^{7,14,22}$ The extrinsic factors like ultraviolet radiation, daily handling, temperature, air pollution, water absorption, and adsorption can also cause degradation of a silicone. ${ }^{1-3,5,7,8,10,13-17,22}$ According to Goiato et $\mathrm{al}^{9}$ and Mancuso et al, ${ }^{15}$ the use of 1,008 hours of accelerated aging (in vitro) corresponds to 1 year of constant use of a silicone prosthesis by the patient.9.15 Therefore, if a silicone prosthesis generally has a maximum clinical durability of 1 year, ${ }^{2,4-}$ $7,10,13,15$ aging for 1,008 hours (in vitro) is sufficient to simulate a clinical situation.

Paravina et al reported that the perceptibility threshold and the acceptability threshold are thresholds used to assess the color changes of dental materials. ${ }^{25}$ According to some authors, a $\Delta \mathrm{E}<1$ represents a visually imperceptible color change, a $\Delta \mathrm{E} \geq 1.0$ represents a visually perceptible color change, a $\Delta \mathrm{E}<3.3$ represents a clinically acceptable color change, and a $\Delta E \geq 3.3$ represents a clinically unacceptable color change for a material. ${ }^{20,26,27}$ In addition, in the literature, it is also possible to find some authors who report a $\Delta \mathrm{E}<3.7$ for a clinically acceptable color change of a material. ${ }^{5,21-23}$ In the present study, the color alteration in each group was lower than 3.3 ( - Table 1). Therefore, both groups showed clinically acceptable values.

The $\mathrm{ZnO}$ is used in the manufacture of sunscreens to protect human skin against ultraviolet rays because it has a high refractive index. ${ }^{3}$ In this study, the acceptability of color values after accelerated aging can be explained by the presence of $\mathrm{ZnO}$ nanoparticles in both groups. According to Nobrega et al, as the nanoparticles are smaller than the ultraviolet light wavelength, their electrons vibrate when they are hit by this radiation, thereby dissipating a portion of the light while absorbing another. ${ }^{3}$ Thus, $\mathrm{ZnO}$ can absorb and disperse ultraviolet rays, forming a protection for the silicone.,19

Extrinsic pigmentation is essential for the manufacture of a silicone prosthesis, since only intrinsic pigmentation may not adequately simulate the human skin color, from a clinical point of view. The findings of this study are important for both dentist and patient, since extrinsic pigmentation caused acceptable changes in the silicone color after aging. Thus, an extrinsic pigmentation applied to a prosthesis would not be a cause of concern for the dentist and patient over time, based on the color change. Therefore, based on this study and the color property, extrinsic pigmentation is clinically indicated.

The group factor showed no statistical difference $(p=0.214)$ based on the hardness property ( - Table 3 ), indicating that the presence of an extrinsic pigmentation did not change the hardness of the silicone. However, the period factor

Table 3 Two-way repeated measures analysis of variance for silicone Shore A hardness

\begin{tabular}{|l|l|l|l|l|l|}
\hline Source & SS & df & MS & F & $p$-Value \\
\hline Group & 11.0250 & 1 & 11.025 & 1.5832 & 0.214 \\
\hline Period & 42.0250 & 1 & 42.025 & 6.0347 & $0.018^{\mathrm{a}}$ \\
\hline Group $\times$ period & 2.0250 & 1 & 2.025 & 0.2908 & 0.599 \\
\hline Residue & 250.7000 & 36 & 6.9639 & & \\
\hline Total & 305.7750 & 39 & & & \\
\hline
\end{tabular}

andicates a statistical difference $(p<0.05)$.

Abbreviations: SS, Sum of Square; df, degree of freedom; MS, Mean Squares. 
showed that there was a reduction in the hardness of the silicone after aging $(p<0.05)$ ( - Tables 2 and $\mathbf{3}$ ). Thus, the accelerated aging caused a statistically significant reduction in the hardness of the silicone used. However, this result was considered clinically acceptable, since acceptable changes in hardness vary from 25 to 35 Shore A units for a silicone prosthesis.,3,3,13 Therefore, based on this study and the hardness property, extrinsic pigmentation is clinically indicated.

According to Tetteh et al, ${ }^{1}$ the weathering can induce changes in physical, mechanical, and chemical characteristics of polymers. ${ }^{1}$ The degradation of a polymer due to weathering is the result of a combined action of oxygen and sunlight (photo-oxidative attack) on the chemical structure of this material. ${ }^{1}$ This degradation causes an initial formation of free radicals, reaction of free radicals with oxygen, production of polymer oxy- and peroxy-radicals, and secondary polymer radicals, resulting in chain scission. ${ }^{1}$ In addition, a reaction of differentfree radicals with each othercan resultin crosslinking. It is also important to mention that a crosslinking can occur due to the formation of bonds between existing monomers or bonds between chains. ${ }^{1}$ In this study, accelerated aging may have caused this set of events, resulting in a reduction in the hardness of the samples.

Nobrega et $\mathrm{al}^{3}$ and Nobrega et $\mathrm{al}^{5}$ can also explain the reduction in the hardness of the samples in this study after aging., 3,5 This can have happened because most polymers contain aromatic rings and $\mathrm{C}=\mathrm{C}$ bonds in their structures. ${ }^{5}$ Aromatic rings and $\mathrm{C}=\mathrm{C}$ bonds can absorb ultraviolet rays during accelerated aging. ${ }^{5}$ When a polymer molecule absorbs ultraviolet light, this energy promotes instability in the molecular aging., ${ }^{3,5}$ The excess energy can be transmitted by excitation from one molecule to another, allowing the first molecule to regain its stability. ${ }^{3,5}$ In this way, affected groups can return to their original state by releasing energy in the form of longer wavelengths, such as visible light or heat., ${ }^{3,5}$ However, a photochemical degradation occurs when this excess energy is released, contributing to molecule deterioration. ${ }^{3,5}$

A limitation of the present study was the lack of studies with methodologies similar to those used in the present study for comparisons between findings. Thus, further studies on facial silicones and extrinsic pigmentation are needed.

\section{Conclusion}

In this study, all the hardness and color results of the silicone used were clinically acceptable, regardless of the presence of extrinsic pigmentation.

\section{Conflict of Interest}

None declared.

\section{References}

1 Tetteh S, Bibb RJ, Martin SJ. Mechanical and morphological effect of plant based antimicrobial solutions on maxillofacial silicone elastomer. Materials (Basel) 2018;11(6):925

2 Goiato MC, Pesqueira AA, Santos DM, Dekon SF. Evaluation of hardness and surface roughness of two maxillofacial silicones following disinfection. Braz Oral Res 2009;23(1):49-53
3 Nobrega AS, Andreotti AM, Moreno A, Sinhoreti MA, Dos Santos DM, Goiato MC. Influence of adding nanoparticles on the hardness, tear strength, and permanent deformation of facial silicone subjected to accelerated aging. J Prosthet Dent 2016;116(4):623-629.e1

4 Cifter ED, Ozdemir-Karatas M, Cinarli A, Sancakli E, Balik A, Evlioglu G. In vitro study of effects of aging and processing conditions on colour change in maxillofacial silicone elastomers. BMC Oral Health 2019;19(1):122

5 Nobrega AS, Malavazi EM, Melo Neto CLM, et al. Influence of different pigment incorporation methods on color, dimensional stability, and detail reproduction of silicones. Eur J Dent 2019;13(3):399-404

6 Kiat-Amnuay S, Mekayarajjananonth T, Powers JM, Chambers MS, Lemon JC. Interactions of pigments and opacifiers on color stability of MDX4-4210/type A maxillofacial elastomers subjected to artificial aging. J Prosthet Dent 2006;95(3):249-257

7 dos Santos DM, Goiato MC, Moreno A, Pesqueira AA, Haddad MF. Influence of pigments and opacifiers on color stability of an artificially aged facial silicone. J Prosthodont 2011;20(3):205-208

8 Guiotti AM, Goiato MC, dos Santos DM. Evaluation of the Shore A hardness of silicone for facial prosthesis as to the effect of storage period and chemical disinfection. J Craniofac Surg 2010;21(2):323-327

9 Goiato MC, Nobrega AS, Freitas da Silva EV, et al. Tear strength analysis of MDX4-4210 and A-2186 silicones with different intrinsic pigments incorporated by mechanical and industrial methods. Int J Dent 2019;2019:2573095

10 Goiato MC, Pesqueira AA, dos Santos DM, Zavanelli AC, Ribeiro Pdo. Color stability comparison of silicone facial prostheses following disinfection. J Prosthodont 2009;18(3):242-244

11 Rahman AM, Jamayet NB, Nizami MM, Johari Y, Husein A, Alam MK. Effect of aging and weathering on the physical properties of maxillofacial silicone elastomers: a systematic review and meta-analysis. J Prosthodont 2019;28(1):36-48

12 Sonnahalli NK, Chowdhary R. Effect of adding silver nanoparticle on physical and mechanical properties of maxillofacial silicone elastomer material-an in-vitro study. J Prosthodont Res 2020. Doi: 10.1016/j.jpor.2019.12.001

13 Santos DM, Goiato MC, Moreno A, et al. Effect of addition of pigments and opacifier on the hardness, absorption, solubility and surface degradation of facial silicone after artificial ageing. Polym Degrad Stabil 2012;97:1249-1253

14 Mancuso DN, Goiato MC, Santos DM. Color stability after accelerated aging of two silicones, pigmented or not, for use in facial prostheses. Braz Oral Res 2009;23(2):144-148

15 Mancuso DN, Goiato MC, Dekon SF, Gennari-Filho H. Visual evaluation of color stability after accelerated aging of pigmented and nonpigmented silicones to be used in facial prostheses. Indian J Dent Res 2009;20(1):77-80

16 Pesqueira AA, Goiato MC, Dos Santos DM, Haddad MF, Moreno A. Effect of disinfection and accelerated ageing on dimensional stability and detail reproduction of a facial silicone with nanoparticles. J Med Eng Technol 2012;36(4):217-221

17 Pesqueira AA, Goiato MC, dos Santos DM, et al. Effect of disinfection and accelerated aging on color stability of colorless and pigmented facial silicone. J Prosthodont 2011;20(4):305-309

18 Mitra A, Choudhary S, Garg H, H G J. Maxillofacial prosthetic materials- an inclination towards silicones. J Clin Diagn Res 2014;8(12):ZE08-ZE13

19 Akash RN, Guttal SS. Effect of incorporation of nano-oxides on color stability of maxillofacial silicone elastomer subjected to outdoor weathering. J Prosthodont 2015;24(7):569-575 
20 Vichi A, Ferrari M, Davidson CL. Color and opacity variations in three different resin-based composite products after water aging. Dent Mater 2004;20(6):530-534

21 Goiato MC, Nóbrega AS, dos Santos DM, Andreotti AM, Moreno A. Effect of different solutions on color stability of acrylic resin-based dentures. Braz Oral Res 2014;28:1-7

22 Goiato MC, Santos DM, Souza JF, Moreno A, Pesqueira AA. Chromatic stability of acrylic resins of artificial eyes submitted to accelerated aging and polishing. J Appl Oral Sci 2010;18(6):641-645

23 Imirzalioglu P, Karacaer O, Yilmaz B. Ozmen Msc I. Color stability of denture acrylic resins and a soft lining material against tea, coffee, and nicotine. J Prosthodont 2010;19(2):118-124

24 ASTM G53-96, Practice for Operating Light- and WaterExposure Apparatus (Fluorescent UV-Condensation Type) for Exposure of Nonmetallic Materials (Withdrawn 2000). Available at: www.astm.org. Accessed 1996

25 Paravina RD, Ghinea R, Herrera LJ, et al. Color difference thresholds in dentistry. J Esthet Restor Dent 2015;27(Suppl 1): S1-S9

26 Oğuz S, Mutluay MM, Doğan OM, Bek B. Color change evaluation of denture soft lining materials in coffee and tea. Dent Mater J 2007;26(2):209-216

27 ElSayad II. Color and translucency of finished and unfinished esthetic restorative materials after staining and bleaching. Saudi Dent J 2018;30(3):219-225 